\title{
Effects of Caffeine in Parkinson's Disease: From Neuroprotection to the Management of Motor and Non-Motor Symptoms
}

\author{
Rui D.S. Prediger* \\ Departamento de Farmacologia, Centro de Ciências Biológicas, and Centro de Neurociências Aplicadas (CeNAp), \\ Hospital Universitário; Universidade Federal de Santa Catarina, UFSC, Florianópolis-SC, Brazil
}

\begin{abstract}
Parkinson's disease (PD) is the second most common neurodegenerative disorder affecting approximately $1 \%$ of the population older than 60 years. Classically, PD is considered to be a motor system disease and its diagnosis is based on the presence of a set of cardinal motor signs (rigidity, bradykinesia, rest tremor) that are consequence of a pronounced death of dopaminergic neurons in the substantia nigra pars compacta. Nowadays there is considerable evidence showing that non-dopaminergic degeneration also occurs in other brain areas which seems to be responsible for the deficits in olfactory, emotional and memory functions that precede the classical motor symptoms in PD. The present review attempts to examine results reported in epidemiological, clinical and animal studies to provide a comprehensive picture of the antiparkinsonian potential of caffeine. Convergent epidemiological and pre-clinical data suggest that caffeine may confer neuroprotection against the underlying dopaminergic neuron degeneration, and influence the onset and progression of PD. The available data also suggest that caffeine can improve the motor deficits of $\mathrm{PD}$ and that adenosine $\mathrm{A}_{2 A}$ receptor antagonists such as istradefylline reduces OFF time and dyskinesia associated with standard 'dopamine replacement' treatments. Finally, recent experimental findings have indicated the potential of caffeine in the management of non-motor symptoms of PD, which do not improve with the current dopaminergic drugs. Altogether, the studies reviewed provide strong evidence that caffeine may represent a promising therapeutic tool in PD, thus being the first compound to restore both motor and non-motor early symptoms of PD together with its neuroprotective potential.
\end{abstract}

Keywords: Adenosine receptors, animal models, caffeine, learning and memory, motor deficits, neuroprotection, olfactory system, Parkinson's disease

\section{INTRODUCTION}

At the beginning of the nineteenth century, when James Parkinson first described the disorder that bears his name [1], life expectation was no longer than 45 years. Nowadays, life expectancy is near 80 years, and

${ }^{*}$ Correspondence to: Rui D.S. Prediger, PhD, Departamento de Farmacologia, Universidade Federal de Santa Catarina, Campus Trindade, 88049-900, Florianópolis, SC, Brazil. Tel.: +55 483721 9491; Fax: +55 483337 5479; E-mail: ruidsp@ hotmail.com. the prevalence of Parkinson's disease (PD) is generally estimated at $0.3 \%$ of the entire population and about $1 \%$ in people over 60 years of age [2]. Since the incidence of the disease increases with age (the most important risk factor), it is likely that the number of people suffering from PD will rise steadily in the future.

Classically, PD is considered to be a motor system disease and its diagnosis is based on the presence of a set of cardinal motor signs (e.g., rigidity, bradykinesia, rest tremor and postural reflex disturbance). These symptoms of PD mainly result from the progressive de- 
generation of dopamine neurons of the substantia nigra pars compacta $(\mathrm{SNc})$, which causes a consequent reduction of dopamine levels in the striatum [3]. Dopaminereplacement therapy has dominated the treatment of PD since the early 1960s and although the currently approved antiparkinsonian agents offer effective relief of the motor deficits, especially in the early stages of the disease, they have not been found to alleviate the underlying dopaminergic neuron degeneration, and drug efficacy is gradually lost [4]. Moreover, another major limitation of chronic dopaminergic therapy is the numerous adverse effects such as the development of abnormal involuntary movements (namely dyskinesia), psychosis and behavioral disturbance (e.g., compulsive gambling, hypersexuality) [5].

Dopamine replacement therapy is based on the importance of nigral dopaminergic cell loss and the ensuing striatal dopamine depletion for the onset of motor symptoms. However, the neurodegenerative processes that lead to sporadic PD begin many years before the appearance of the characteristic motor symptoms, and additional neuronal fields and neurotransmitter systems are also involved in PD, including the anterior olfactory structures, dorsal motor nucleus of vagus, caudal raphe nuclei, locus coeruleus, the autonomic nervous system, hippocampus, and the cerebral cortex [6] (Fig. 1). Accordingly, cholinergic, adrenergic, and serotoninergic neurons are also lost, which seems to be responsible for the non-motor symptoms of PD encompassing olfactory and memory impairments, sleep abnormalities, and depression, as well as gastrointestinal disturbance, which precede the classical motor symptoms [7]. Non-motor features of PD invariably do not respond to dopaminergic medication and are probably the major current challenge faced in the clinical management of PD [7].

Therefore, the limitations of the current pharmacological treatments of PD have led to extensive investigation of novel non-dopaminergic drugs that may provide alternative or adjunctive treatment for the relief of both motor and non-motor symptoms with a reduced profile of side-effects, as well as to the discovery of compounds to modify the course of PD. Over the last decade, several lines of evidence have suggested the potential of caffeine in the treatment of PD and an increasing number of studies have tested the potentially beneficial effects of caffeine (and more selective adenosine $\mathrm{A}_{2 A}$ receptor antagonists) in different animal models and PD patients (Fig. 2).

Convergent epidemiological and pre-clinical data suggest that caffeine may confer neuroprotection

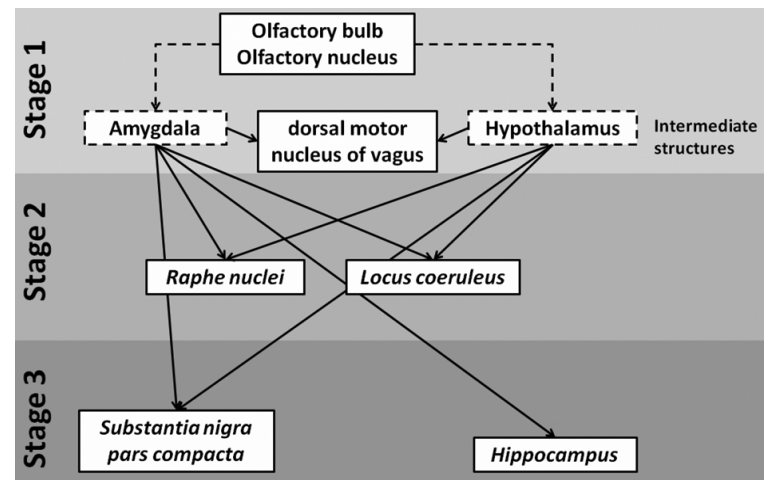

Fig. 1. Schematic illustration of the potential spread of dysfunction in different brain regions in Parkinson's disease during the first three stages, using the Braak's staging system [6], until the substantia nigra pars compacta is affected.

against the underlying dopaminergic neuron degeneration and can influence the onset and progression of PD. Indeed, the available data also suggest that caffeine, through the blockade of adenosine $\mathrm{A}_{2 A}$ receptors in striatopallidal neurons, can improve the motor deficits of $\mathrm{PD}$ and that $\mathrm{A}_{2 A}$ receptor antagonists such as istradefylline reduce OFF time and dyskinesia associated to standard 'dopamine replacement' treatments. Finally, recent experimental findings have indicated the potential of caffeine in the management of non-motor symptoms (e.g., depression, olfactory and memory dysfunction) of PD, which do not improve with the current dopaminergic drugs. The present review attempts to examine results reported in epidemiological, clinical and animal studies to provide a comprehensive picture of the antiparkinsonian potential of caffeine.

\section{CAFFEINE AS A NEUROPROTECTIVE STRATEGY IN PARKINSON'S DISEASE}

Current research on PD is largely devoted to investigating the etiology of the disease with the aim of identifying preventive rather than merely symptomatic treatments. Convergent epidemiologic and experimental evidence have suggested caffeine and selective adenosine $\mathrm{A}_{2 A}$ receptor antagonists as novel potential strategies to attenuate dopaminergic neurodegeneration in PD. In a 30-year follow-up study of 8,004 JapaneseAmerican men in the Honolulu Heart Program, Ross and colleagues [8] reported an inverse relationship between consumption of the non-selective adenosine antagonist caffeine and the risk of developing PD 20 years later. The age- and smoking-adjusted risk of PD was five times higher among men who reported no coffee 


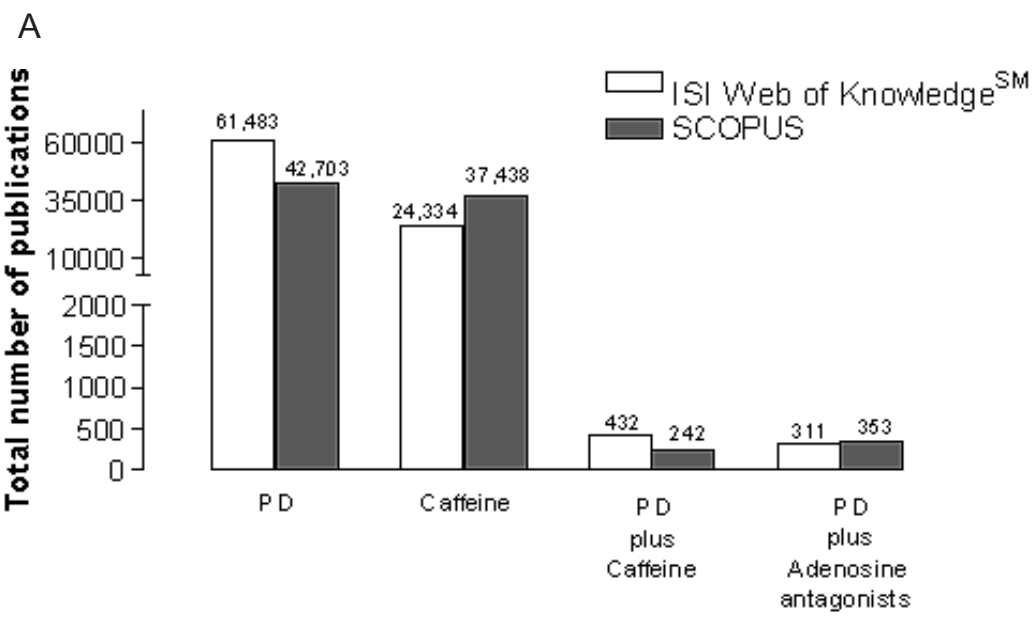

B ISI Web of Knowledge ${ }^{\text {SM }}$
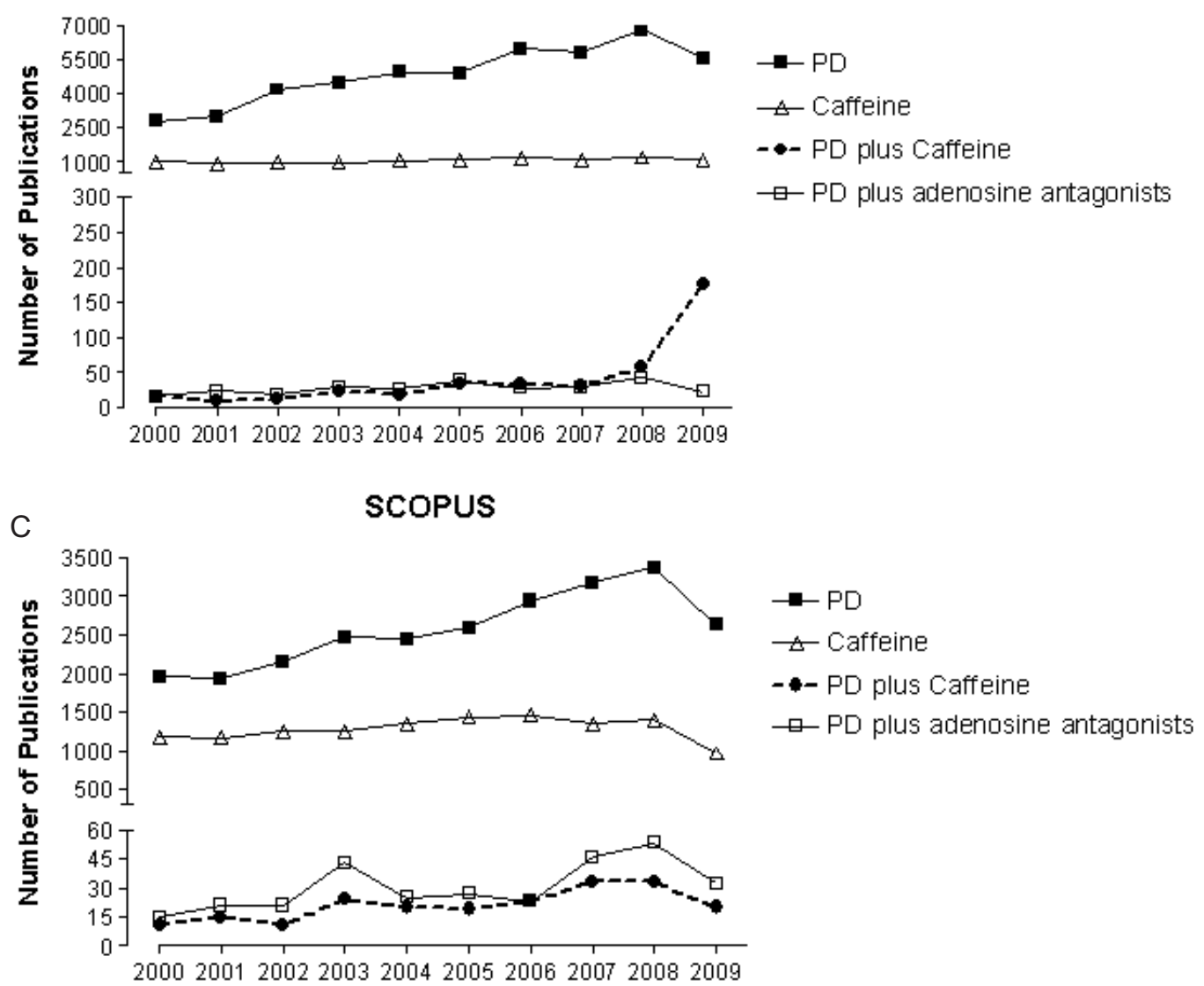

Fig. 2. Number of publications containing the keywords "Parkinson's disease" (PD), "caffeine", "PD plus caffeine" and "PD plus adenosine antagonists" found in the main databases analyzed. Panel A illustrates the total number of publications (time spam "all years") obtained for the queries comparing ISI Web of Knowledge $\mathrm{e}^{S M}$ and SCOPUS. A time-line concerning the publications from year 2000 until October $23^{r d}$ of the year 2009 obtained from ISI Web of Knowledge ${ }^{S M}$ and SCOPUS databases are shown in panels B and C, respectively. In the ISI Web of Knowledge ${ }^{S M}$, data were generated using the keyword "Parkinson disease" rather than "Parkinson's disease", which caused a syntax error because of the apostrophe in this database; This did not occur with SCOPUS. 
consumption compared with men who reported a daily consumption of $28 \mathrm{oz}$ or more of coffee [8]. This finding was subsequently reinforced by further large prospective studies, which observed a similar inverse relationship between the consumption of caffeinated (but not decaffeinated) coffee and the risk of developing PD. These included the Health Professionals' Follow-Up Study and the Nurses' Health Study, involving 47,351 men and 88,565 women [9], and the Finnish Mobile Clinic Health Examination Survey, involving 19,518 men and women [10]. Men with consumption of tea and other caffeinated beverages had reduced risk of $\mathrm{PD}$ compared with men who were not regular caffeine drinkers ( $<1 \mathrm{cup} /$ day $)$, whereas no association was found with the consumption of decaffeinated coffee [8]. Interestingly, a 50\% reduction of the risk of developing PD was observed among men with consumption of as low as one cup of caffeine per day when compared with men consuming no caffeine. These studies firmly established a relationship between increased caffeine consumption and the decreased risk of developing PD in men [8-10]. These findings raise the exciting possibility that caffeine as well as adenosine $\mathrm{A}_{2 A}$ receptor antagonists may reduce the risk of developing PD by attenuating the degeneration of nigrostriatal dopaminergic neurons. In this context, caffeine has been included in a list of the twelve most promising neuroprotective agents for clinical trials in PD [11]. Curiously, in women, caffeine consumption is also linked to a reduced risk of PD but only among those who were not under hormone-replacement therapy [12]. Similar results have been found in an animal model of PD, where estrogen therapy prevented the neuroprotection by caffeine against nigrostriatal dopaminergic death [13].

The neuroprotective potential of caffeine in PD was further demonstrated in different animal models. Caffeine, when co-administered with 1-methyl-4-phenyl 1,2,3,6-tetrahydropyridine (MPTP) to mice at doses (5 to $30 \mathrm{mg} / \mathrm{kg}$ ) comparable to the doses consumed by humans, dose-dependently attenuates the MPTP-induced loss of striatal dopamine neurons [14]. This protective effect of caffeine was observed with different MPTP exposure regiments (single and multiple doses) and in several mouse strains [14]. Furthermore, immunohistochemical analysis shows that caffeine can attenuate the MPTP-induced loss of nigral dopaminergic neurons [15]. Of high importance, caffeine-mediated neuroprotection apparently does not develop tolerance after continuous treatment, whereas nearly complete tolerance develops for its motor stimulant effect [16]. The neuroprotective effects of caffeine have been attributed to an action on adenosine $\mathrm{A}_{2 A}$ receptors since complementary studies with selective blockade of adenosine $\mathrm{A}_{2 A}$ (but not $\mathrm{A}_{1}$ ) receptors, through pharmacologic or genetic strategies, reported similar neuroprotective effects in the MPTP- $[14,15,17]$ and 6-hydroxydopamine (6-OHDA) rodent models of PD [18]. However, no information is available to date as to whether the neuroprotective effects of caffeine or selective adenosine $\mathrm{A}_{2 \mathrm{~A}}$ receptor antagonists can be extended to non-human primate models of PD. Nevertheless, the complimentary genetic and pharmacologic studies provide compelling evidence that caffeine reduces dopaminergic neurotoxicity in animal models of PD through the antagonism of adenosine $\mathrm{A}_{2 A}$ receptors.

Although the exact molecular mechanisms underlying caffeine protection against the loss of dopaminergic neurons remains to be elucidated, it is important to emphasize that the neuroprotection by adenosine $\mathrm{A}_{2 \mathrm{~A}}$ receptor antagonism extends beyond PD models [19, 20]. Chronic stressful stimuli cause an increased expression and density of adenosine $\mathrm{A}_{2 A}$ receptors in animal models of PD [21,22], epilepsy [23], diabetes [24], and restraint stress [25]. Moreover, adenosine $\mathrm{A}_{2 \mathrm{~A}}$ receptor antagonists confer neuroprotection against a broad spectrum of brain injury such as that induced by excitotoxicity [26-28], ischemia [29-33], and that associated with models of Huntington's disease [34] and Alzheimer's disease [35-37]. Therefore, the blockade of adenosine $\mathrm{A}_{2 A}$ receptors confers neuroprotection in diverse brain regions ranging from substantia nigra, striatum to hippocampus and cortex, and against a variety of brain noxious stimuli.

Studies on neuroprotection exerted by caffeine and selective $\mathrm{A}_{2 A}$ receptor antagonists are numerous and several mechanisms have been implicated in these effects. At this moment, particular attention is paid to the role of $\mathrm{A}_{2 A}$ receptors in modulating glutamate release and glutamate uptake, as well as neuroinflammation (see Fig. 3), since these neurochemical changes have been associated with a variety of neuropathological processes, namely in PD models. Despite the multiple roles of glutamate in the brain as a protein constituent, neurotransmitter, and in the intermediary metabolism (for review see [38]), it can be highly toxic to neurons, a phenomenon known as "excitotoxicity", the process by which the over-activation of excitatory neurotransmitter receptors leads to neuronal cell death [39] through either rapid necrosis or delayed apoptosis of the neuron, depending on the severity of the insult [40]. In neurons, N-methyl-D-aspartic acid (NMDA) receptors, 


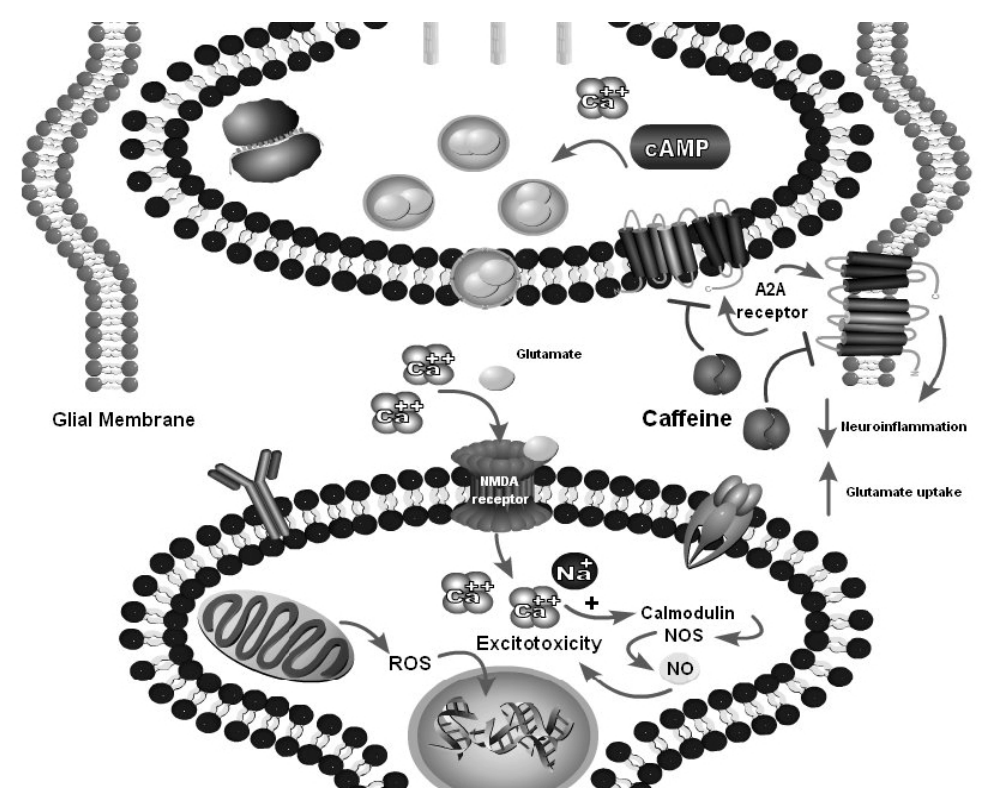

Fig. 3. Molecular mechanisms probably involved in the neuroprotective effects of caffeine and selective adenosine $\mathrm{A}_{2 \mathrm{~A}}$ receptor antagonists. Adenosine $\mathrm{A}_{2 A}$ receptors exert significant modulation of glutamate overflow by pre-synaptic and glial mechanisms and the blockade of adenosine $\mathrm{A}_{2 A}$ receptors can represent a neuroprotective strategy by preventing glutamate excitotoxicity that is present in several neurodegenerative diseases including Parkinson's disease. Alternatively, the neuroprotection associated to the blockade of adenosine $\mathrm{A}_{2 \mathrm{~A}}$ receptors may involve the modulation of neuroinflammation since activation of adenosine $\mathrm{A}_{2 A}$ receptors produce complex effects in glial cells, including up-regulation of cyclo-oxygenase 2 and nitric oxide syntase, production of pro-inflammatory prostaglandins and cytokines and microglial activation.

which are highly permeable to calcium and distributed widely in the central nervous system (CNS) neurons, are the major initiators of excitotoxicity [41]. In PD, depletion of nigrostriatal dopamine results in disinhibition of striatal neurons which triggers glutamatergic overactivity [42].

As summarized in Fig. 3, adenosine $\mathrm{A}_{2 A}$ receptors modulate glutamate release from nerve terminals and its clearance from astrocytes $[19,43]$. Several studies identified adenosine $\mathrm{A}_{2 A}$ receptors as being responsible for the enhanced release of glutamate in noxious situations $[28,44,45]$. This hypothesis is particularly attractive because $\mathrm{A}_{2 A}$ receptors are found in approximately $30 \%$ of glutamatergic pre-synaptic terminals in hippocampus [23], and because the activation of $\mathrm{A}_{2 \mathrm{~A}}$ receptors can enhance glutamate release in the hippocampus and cortex of intact animals under normal and pathophysiological conditions [46]. More recently, adenosine $\mathrm{A}_{2 A}$ receptor modulation of glial function has emerged as an additional mechanism by which $\mathrm{A}_{2 A}$ receptor antagonists may modulate glutamate release and consequently neuronal cell death in CNS. Activation of adenosine $\mathrm{A}_{2 A}$ receptors in cultured astrocytic glial cells derived from the cortex or brainstem was found to enhance glutamate efflux, whereas $\mathrm{A}_{2 \mathrm{~A}}$ receptor blockade reduced the levels of extracellular glu- tamate $[47,48]$. Thus, $\mathrm{A}_{2 A}$ receptors exert significant modulation of glutamate overflow by pre-synaptic and glial mechanisms, and the blockade of adenosine $\mathrm{A}_{2 \mathrm{~A}}$ receptors can be a neuroprotective strategy by preventing glutamate excitotoxicity that is present in several neurodegenerative diseases, including PD.

Another possible mechanism by which the treatment with caffeine and selective adenosine $\mathrm{A}_{2 A}$ receptor antagonists confers neuroprotection may involve the modulation of neuroinflammation. The hallmark of neuroinflammation is glial (microglia and astrocytes) activation. Microglia, the resident immune cells in the brain, are sensitive to even minor disturbances in CNS homeostasis and become readily activated during most neuropathological conditions, such as PD, Alzheimer's disease, multiple sclerosis, AIDS dementia, trauma, and stroke (for recent review see [49]). Activated microglia cells are thought to contribute to neuronal damage via the release of pro-inflammatory and neurotoxic factors, such as tumor necrosis factor alpha (TNF- $\alpha$ ) and interleukin $1 \beta$ (IL-1 $\beta$ ), reactive nitrogen species, proteases, reactive oxygen species, eicosanoids, and excitatory amino acids [49]. Intriguingly, in the mature brain the density of resting microglia in the substantia nigra is significantly higher than in other brain regions, which might be one of the reasons why dopamine- 
containing neurons are extremely vulnerable to oxidative stress in PD [50]. An accumulation of extracellular adenosine in inflamed tissues has been reported [51,52]. However, such an anti-inflammatory action of adenosine in the brain is still a matter of debate [55]. Whereas the activation of adenosine $\mathrm{A}_{2 A}$ receptors prevents peripheral inflammation $[53,54]$, there is a paradoxical modulation of neuroinflammation by adenosine $\mathrm{A}_{2 \mathrm{~A}}$ receptors [55]; in fact, when neuronal damage is the primary trigger of neuroinflammation, it is the blockade of $\mathrm{A}_{2 A}$ receptors that prevents neuroinflammation [55].

This contradictory modulation by adenosine $\mathrm{A}_{2 A}$ receptors can reflect the complexity of action of these receptors on neuronal, glial, and vascular components, which may have distinct effects in brain injury $[20,55]$. Apparently, activation of adenosine $\mathrm{A}_{2 A}$ receptors produce complex effects in glial cells, including regulation of glutamate efflux (as described above), up-regulation of cyclo-oxygenase 2 and nitric oxide syntase, production of pro-inflammatory prostaglandins and cytokines, and microglial activation [56,57]. Consequently, activation of brain adenosine $\mathrm{A}_{2 A}$ receptors might also induce potential deleterious effects by exacerbating neuroinflammatory process. Consistent with this notion, Pierry and colleagues [17] reported that the neuroprotection afforded by the selective adenosine $\mathrm{A}_{2 A}$ receptor antagonist KW-6002 against MPTP neurotoxicity is associated with inhibition of microglial activation in the substantia nigra. More recently, Yu et al. [58] showed that MPTP administration increased the $\mathrm{A}_{2 A}$ receptors density in microglia and astrocytes and that neuroprotection against dopaminergic neurotoxicity upon blockade of adenosine $\mathrm{A}_{2 A}$ receptors was correlated with their ability to influence the MPTP-induced microglial and astrocytic activation.

A better understanding of how the multiple actions of $\mathrm{A}_{2 A}$ receptors influence survival of dopaminergic neurons might further consolidate caffeine and selective adenosine $\mathrm{A}_{2 A}$ receptor antagonists as potential neuroprotective agents for the treatment of PD.

\section{CAFFEINE AS A PALLIATIVE TREATMENT FOR THE MOTOR IMPAIRMENTS IN PARKINSON'S DISEASE}

A logical rationale to conceive a non-dopaminergic therapy for PD is to reverse the disruption to basal ganglia function by moving beyond the damaged dopaminergic input to the striatum and focusing on the activity of striatal output pathways, which is known to be im- portant in the expression of motor symptoms and the onset and/or expression of dyskinesia [59]. At present time, there is an extensive literature demonstrating the ability of caffeine and selective adenosine $\mathrm{A}_{2 \mathrm{~A}}$ receptor antagonists to modulate basal ganglia neurotransmission, which has been shown to be associated with improved motor function in diverse experimental models of PD [60,61]. In rodents, caffeine as well as selective $\mathrm{A}_{2 A}$ receptor antagonists increase locomotor activity in MPTP-treated or reserpinized mice and reverse haloperidol-induced catalepsy [62,63]. A pioneering study by Fuxe and Ungerstedt [64] reported that caffeine induced contralateral turning in unilaterally 6OHDA-lesioned rats. Subsequently other authors observed that the efficacy of caffeine in inducing turning behavior was observed only in 6-OHDA-lesioned rats receiving several priming doses of dopamine agonists, which in turn produced a supersensitive response to caffeine [65-67]. Indeed, the selective blockade of adenosine $\mathrm{A}_{2 A}$ receptors by istradefylline or $\mathrm{SCH}$ 58261 increases contralateral rotation induced by LDOPA or by stimulation of dopamine receptors in unilaterally 6-OHDA-lesioned rats [68-70]. Moreover, in 6-OHDA-lesioned rats rendered dyskinetic by prior treatment with L-DOPA, istradefylline produced an additive reduction in motor disability with L-DOPA, without worsening dyskinesia [71,72].

The classical triad of the cardinal motor features of PD includes muscle rigidity and tremor at rest in addition to bradykinesia (i.e., slow movements). Thus, additional features of $\mathrm{A}_{2 A}$ receptor antagonists of particular clinical relevance would be an ability to relieve muscle rigidity and to counteract parkinsonian tremor. Correa et al. [73] have demonstrated that the adenosine $\mathrm{A}_{2 A}$ receptor antagonist KF 17837 reverses the locomotor deficits and tremulous jaw movements induced by haloperidol in rats. Moreover, muscle rigidity (e.g., increased resistance to passive movement) induced by the dopamine-depleting agent reserpine or by the preferential dopamine $\mathrm{D}_{2}$ receptor antagonist haloperidol can be reduced by the $\mathrm{A}_{2 A}$ receptor antagonist $\mathrm{SCH}$ 58261 or eliminated by a synergistic combination of L-DOPA plus SCH 58261 [74].

The ability of adenosine $\mathrm{A}_{2 A}$ receptor antagonists to improve motor disruption has been also documented in MPTP-treated non-human primates [75,76]. In MPTP-treated common marmosets, oral administration of istradefylline $(0.5-100 \mathrm{mg} / \mathrm{kg})$ increased locomotor activity for up to $9 \mathrm{~h}$ [75]. This effect was dosedependent, with the greatest improvement observed at $10 \mathrm{mg} / \mathrm{kg}$ and with no additional benefit at higher dos- 
es. A notable feature of $\mathrm{A}_{2 A}$ receptor antagonists revealed by the experimental studies is their ability to enhance motor activity with reduced propensity to elicit dyskinesia [75,76]. For example, in L-DOPA-primed MPTP-treated cynomolgus monkeys, istradefylline at doses of 60 and $90 \mathrm{mg} / \mathrm{kg}$ significantly improved locomotor function, with an efficiency comparable to that observed with L-DOPA (50 mg/kg), but with little or no dyskinesia [76]. This observation raises the possibility that in PD patients with established dyskinesia, istradefylline monotherapy might provide motor benefit without eliciting dyskinesia. Additionally, chronic intermittent therapy using L-DOPA (or a dopamine agonist) can conspire with the hypodopaminergic state of PD to produce progressively briefer motor benefits and progressively more disruptive involuntary movements (dyskinesia) in response to each dose. The prevention and suppression of L-DOPA-induced dyskinesia have become major goals for the new non-dopamine approaches. Thus, the effect of adding istradefylline to L-DOPA or dopamine receptor agonists has been also investigated in non-human primate models of PD. For instance, the co-administration of istradefylline with threshold doses of L-DOPA and dopamine $\mathrm{D}_{2}$ receptor agonists (such as quinpirole) provide an additive effect on motor function of MPTP-treated monkeys [77]. Moreover, Bibbiani and colleagues [78] have demonstrated that istradefylline completely prevents the development of dyskinesia induced by continuous apomorphine administration in MPTP-treated monkeys. Taken together, these pre-clinical studies performed in rodents and non-human primate models of $\mathrm{PD}$ have pointed to caffeine and selective adenosine $\mathrm{A}_{2 A}$ receptor antagonists (e.g., istradefylline) as potential drugs to provide a relief of motor symptoms as monotherapy, as well as to potentiate the effects and to prevent the dyskinesia of chronic treatment with L-DOPA and dopamine receptor agonists.

These promising observations in animal models have led to clinical trials in PD patients with the caffeine-derived $\mathrm{A}_{2 A}$ receptor antagonist $(E)$-1,3-diethyl-8-(3,4dimethoxystyryl)-7-methylxanthine (KW-6002) [79, 80]. KW-6002 was shown to potentiate the symptomatic benefits conferred by a reduced dose of L-DOPA in relatively advanced PD and to produce motor enhancement that was comparable with that of an optimal L-DOPA dose [79,80]. Recently, istradefylline 40 $\mathrm{mg}$ /day was compared with placebo as monotherapy in early PD in a 12-week, double-blind, randomized, multi-center study involving 176 subjects [81]. The primary outcome measure was the change from baseline to endpoint in UPDRS motor scores. Although istradefylline provided numerical improvement over placebo, the difference in the primary outcome measure across groups was not statistically significant. These results differ from that obtained in pre-clinical studies in which caffeine and selective adenosine $\mathrm{A}_{2 A}$ receptor antagonists reversed the motor deficits, suggesting that more exhaustive studies of istradefylline (or other adenosine $\mathrm{A}_{2 A}$ receptor antagonists) monotherapy over longer periods and in a larger number of patients should be considered.

On the other hand, randomized, double-blind, placebo-controlled, phase II $[82,83]$ and phase III [84, $85]$ clinical studies were subsequently conducted in PD patients on L-DOPA with motor fluctuations (with or without dyskinesia). The major finding of these recent clinical trials is that istradefylline (20-60 mg/day) reduces OFF time by $0.7-1.2 \mathrm{~h}$. An increase occurs in ON time with dyskinesia, but most of this increase is non-troublesome dyskinesia $[82,83,85]$. However, Guttman [84] reported no significant reduction in OFF time versus placebo with istradefylline ( $10-40 \mathrm{mg} /$ day $)$ in PD patients with motor fluctuations, and the reason for this discrepancy is unknown.

Our understanding of how adenosine $\mathrm{A}_{2 A}$ receptors modulate motor function is based on current models of basal ganglia anatomy and physiology. A detailed review of the anatomy, physiology, and biochemistry of the basal ganglia is beyond the scope of this article and can be found elsewhere [86]. The core components of the basal ganglia are the dorsal and ventral striatum and the globus pallidus (GP). The dorsal striatum is formed by the caudate nucleus and the putamen. Many authors refer to the ventral striatum as the nucleus accumbens (NAc), its main part. The GP consists of an internal (GPi) and an external (GPe) segment and of the ventral pallidum. Due to their reciprocal connections with these core structures, the substantia nigra, ventral tegmental area, and subthalamic nucleus (STN) are considered to be associated basal ganglia structures. The substantia nigra comprises two parts: the substantia nigra pars compacta (SNc), and the substantia nigra pars reticulata $(\mathrm{SNr})[86,87]$. They are thought to mediate the learning and processing of motor acts through the balance between two parallel polysynaptic pathways, the direct (striatonigral) and the indirect (striatopallidal) pathways (Fig. 4).

GABAergic neurons in the direct pathway project directly from the striatum to the GPi-SNr complex. They bear dopamine $\mathrm{D}_{1}$ receptors and contain the peptides substance $\mathrm{P}$ and dynorphin. Striatal GABAergic neu- 


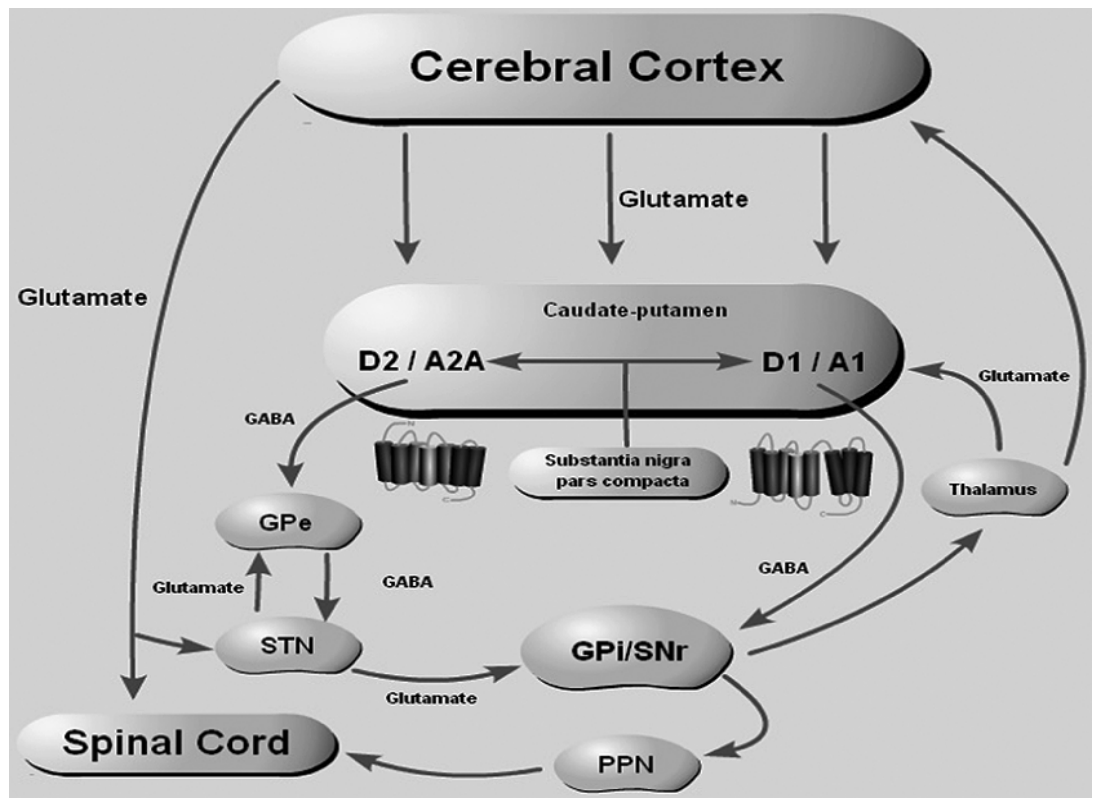

Fig. 4. Simplified diagram of the cortico-basal ganglia network and the possible mechanism by which caffeine and selective adenosine $\mathrm{A}_{2 \mathrm{~A}}$ receptor antagonists improve parkinsonian motor dysfunction through their direct inhibitory influence on striatopallidal neurons, which co-express $\mathrm{A}_{2 A}$ and $\mathrm{D}_{2}$ receptors. The inhibitory influence of the striatonigral "direct" pathway on basal ganglia output (from the $\mathrm{SNr} / \mathrm{GPi}$ complex) is counterbalanced by the disinhibitory influence of the striatopallidal "indirect" pathway to this complex. At the striatal level, dopamine, acting on $\mathrm{D}_{1}$ receptors, facilitates transmission along the direct pathway and inhibits transmission along the indirect pathway throughout $\mathrm{D}_{2}$ receptors. Adenosine enhances the activity of neurons in the indirect pathway via adenosine $\mathrm{A}_{2 A}$ receptors in the striatum and globus pallidus pars externa (GPe). The progressive reduction of striatal dopamine levels in the course of Parkinson's disease (PD) results in an imbalance between the "indirect" and "direct" output pathways leading to increased inhibitory output from the internal GP (GPi) and substantia nigra pars reticulate ( $\mathrm{SNr}$ ) with excess inhibition of thalamocortical neurons, resulting in the reduced movement initiation characteristic of PD. Thus, adenosine $\mathrm{A}_{2 A}$ receptor blockade in PD should result in recovery of GPe activity and decrease excitatory drive from the STN to the GPi-SNr complex, thereby restoring some balance between the direct and the indirect pathways. The schematic is adapted from Schwarzschild et al. [61]. See text for further citations.

rons in the indirect pathway influence the GPi-SNr indirectly via sequential synaptic connections in the GPe and then to the STN. This series of connections comprises: 1) an inhibitory GABAergic projection from the striatum to GPe; 2) an inhibitory GABAergic projection from the GPe to the STN (as well as to the $\mathrm{GPi}-\mathrm{SNr}$ ); and 3) an excitatory glutamatergic projection from the STN to the GPi-SNr. In contrast to striatonigral neurons, striatopallidal neurons express the $\mathrm{D}_{2}$ subtype of dopamine receptors and contain the peptide enkephalin. However, the segregation of the direct and indirect pathways seems to be incomplete, with many projection neurons of the striatum expressing both $\mathrm{D}_{1}$ and $\mathrm{D}_{2}$ receptors [88]. In these cases, one family of dopamine receptors may predominate in each subpopulation of neurons.

At the striatal level, dopamine facilitates motor activity both by exciting $\mathrm{D}_{1}$ receptor-expressing neurons in the direct pathway, and by inhibiting $\mathrm{D}_{2}$ receptorexpressing neurons in the indirect pathway. In the striatum, adenosine $\mathrm{A}_{2 A}$ receptors are mainly expressed on dopamine $\mathrm{D}_{2}$ receptor-bearing striatopallidal neurons $[60,61,87]$. This unique cellular location of $\mathrm{A}_{2 A}$ receptors provides an anatomical basis for the adenosine - dopamine interaction that underlies the motor symptomatic benefits of caffeine and selective adenosine $\mathrm{A}_{2 A}$ receptor antagonists in PD (for review see [60, 61,87]). A large body of experimental evidence shows that adenosine $\mathrm{A}_{2 A}$ receptor agonists inhibit dopamine $\mathrm{D}_{2}$ receptor binding in striatum, $\mathrm{D}_{2}$ receptor-mediated neurotransmitter release, and immediate early gene expression. Conversely, adenosine $\mathrm{A}_{2 A}$ receptor antagonists mimic the effects of dopamine $\mathrm{D}_{2}$ receptor agonists at cellular, neurochemical, and behavioral levels in normal and dopamine-depleted animals [87]. Therefore, the most likely mechanism by which caffeine and selective adenosine $\mathrm{A}_{2 A}$ receptor antagonists improve parkinsonian motor dysfunction probably involves their direct inhibitory influence on striatopallidal neurons, which co-express $\mathrm{A}_{2 A}$ and $\mathrm{D}_{2}$ receptors.

In addition, experimental findings strongly suggest that, besides adenosine $\mathrm{A}_{2 \mathrm{~A}}$ and dopamine $\mathrm{D}_{2}$, 
metabotropic glutamate 5 (mGlu5) receptors are also co-localized post-synaptically in the striatopallidal GABAergic efferent neuron [89]. This co-localization provides a structural framework for the existence of multiple functional interactions of $\mathrm{A}_{2 \mathrm{~A}}, \mathrm{D}_{2}$ and mGlu5 receptors. A potentiation of motor activity has been reported upon combined administration of $\mathrm{A}_{2 \mathrm{~A}}$ and mGlu5 receptor antagonists, together with a synergistic interaction at the level of signal transduction pathways [89-92]. The recent discovery of $\mathrm{A}_{2 A^{-}}$ mGlu5 heteromers in caudate-putamen $(\mathrm{CPu})$ has further strengthened the rationale for studying antiparkinsonian strategies that simultaneously block adenosine $\mathrm{A}_{2 A}$ and mGlu5 receptors [89]. Moreover, striatal cholinergic nerve terminals express adenosine $\mathrm{A}_{2 A}$ receptors, and selective adenosine $\mathrm{A}_{2 A}$ receptor antagonists can reduce the evoked release of acetylcoline in rat $\mathrm{CPu}$ [93]. This seems to represent a novel interesting target for tremor control in PD models.

Altogether, these observations emphasize the role of $\mathrm{A}_{2 A}$ receptors in modulating dopaminergic, glutamatergic and cholinergic neurotransmission in basal ganglia and the potential of $\mathrm{A}_{2 A}$ receptor antagonists for symptomatic treatment of motor impairments in PD.

\section{CAFFEINE AS A PALLIATIVE TREATMENT FOR THE NON-MOTOR IMPAIRMENTS IN PARKINSON'S DISEASE}

As stated in the Introduction, the neurodegenerative processes that lead to sporadic PD begin many years before the appearance of the characteristic motor symptoms and additional neuronal fields and neurotransmitter systems are also involved in PD [6] (Fig. 1). Accordingly, cholinergic, adrenergic and serotoninergic neurons are also lost and this seems to be associated with the non-motor symptoms of PD, which include olfactory and memory impairments, sleep abnormalities and depression, as well as gastrointestinal disturbances that precede the classical motor symptoms [7]. Non-motor features of PD invariably do not respond to dopaminergic medication and probably form the major current challenge faced in the clinical management of PD [7].

Subtle cognitive impairments consisting mainly of executive dysfunction with secondary visuospatial and mnemonic disturbances can be observed in the early stages of PD [94,95]. In about 20-40\% of patients, these problems may eventually proceed to dementia, which constitutes an important risk factor for care- giver distress, decreased quality of life, and nursing home placement. Even non-demented PD patients have been reported to present visuospatial working memory deficits [94-97]. Furthermore, although there are reports of declarative (or episodic) memory impairments in PD [98], they are less severe in comparison to other neurodegenerative disorders such as Alzheimer's disease $[95,98]$. The fact that most of the drugs currently available for PD treatment (such as L-DOPA) are more efficient in alleviating motor rather than cognitive impairments has led many researchers to postulate nondopaminergic mechanisms for the cognitive symptoms of PD [99,100]. On the other hand, animal models are an invaluable tool for studying the pathogenesis and progression of human diseases, as well as for testing new therapeutic intervention strategies. To date, most studies performed with animal models of PD have focused on their ability to induce nigrostriatal dopaminergic pathway damage and motor alterations associated with advanced phases of PD. Because PD is accompanied by alterations in a variety of functions, including anxiety disorders [101], memory deficits [94-100] and olfactory dysfunction [102-104], it seems important to evaluate whether the proposed animal models of PD display alterations of any of these functions. Until recently, no well-accepted model of the early phase of PD was available in the literature. This view has been re-evaluated following the findings that the infusion of MPTP by intranasal (i.n.) route [105-107] or directly into the rat SNc [108-110] causes a partial loss of dopamine neurons and depletion of striatal dopamine that result in olfactory and memory deficits. Corroborating clinical observations, the administration of benserazide/L-DOPA to MPTP-lesioned rats, at a dose that restores the striatal dopamine levels, fails to reverse MPTP-induced learning and memory impairment [110]. The failure of L-DOPA to improve memory deficits in both clinical studies and in bilaterally MPTP-lesioned rats reinforces the adequacy of this animal model to explore the potential of alternative drug therapies for the treatment of PD-related cognitive impairments.

As recently reviewed by Takahashi and colleagues [111], results obtained in different laboratories suggest that caffeine as well as selective adenosine $\mathrm{A}_{1}$ and $\mathrm{A}_{2 A}$ receptor antagonists can improve rodent learning and memory in diverse behavioral tasks [36,112116]. However, few studies have specifically assessed the effects of caffeine or selective adenosine receptor antagonists on the cognitive impairment observed in animal models of PD. Gevaerd et al. [117] were 
the pioneers to report that acute administration of caffeine reverses the impairing effect of MPTP-induced $\mathrm{SNc}$ lesion on the avoidance scores in the training and test sessions of a two-way active avoidance task in rats. Another animal model widely used for investigating symptomatic antiparkinsonian treatments is the systemic administration of reserpine, a drug that inhibits monoamine storage in intracellular granules, and hence causes their depletion in nerve terminals and induces transient hypolocomotion and muscular rigidity $[118,119]$. More recently, the use of low doses of reserpine $(0.5-1.0 \mathrm{mg} / \mathrm{kg})$ in rodents has been proposed as a behavioral approach to study the cognitive deficits [120-122] associated with PD. Prediger and collaborators [121] demonstrated that acute reserpine treatment $(1.0 \mathrm{mg} / \mathrm{kg}$, i.p. $), 24 \mathrm{~h}$ before behavioral analysis, induces pronounced deficits in social recognition memory in rats. Interestingly, the reserpine-induced deficits in social recognition memory were reversed by acute administration (30 min prior to testing) of caffeine (10 or $30 \mathrm{mg} / \mathrm{kg}$, i.p.) or the selective adenosine $\mathrm{A}_{2 A}$ receptor antagonist ZM241385 (0.5 or $1.0 \mathrm{mg} / \mathrm{kg}$, i.p.), but not by the adenosine $\mathrm{A}_{1}$ receptor antagonist DPCPX (0.5 or $3.0 \mathrm{mg} / \mathrm{kg}$, i.p.). However, these same authors had already shown that these doses of DPCPX prolong social recognition memory of non-reserpinized adult rats [115]. These results suggest an increased contribution of adenosine $\mathrm{A}_{2 A}$ receptors (in detriment of $A_{1}$ receptors) in the cognitive deficits induced by reserpine administration in rats.

In addition, the presence of smell loss [102-104] and the pathological involvement of the olfactory pathways in the early stages of PD [6] are in accordance with the tenets of the olfactory vector hypothesis. This hypothesis postulates that some diseases such as PD may be caused or catalyzed by agents that enter the brain via the olfactory mucosa [123]. Consistent with this suggestion, we have recently proposed a new experimental model of PD consisting of a single i.n. administration of MPTP in rats [105,106] and mice [107]. Rodents treated intranasally with MPTP suffered progressive impairments in olfactory, cognitive, and motor functions associated with a time-dependent disruption of dopaminergic neurotransmission in different brain structures conceivably analogous to those observed during different stages of PD [105-107]. The MPTPinduced behavioral impairments in rodents are associated with alterations in the brain antioxidant status and lipid peroxidation [124] and apoptotic cell death mechanisms [106,107]. As can be seen in Fig. 5, rats infused intranasally with MPTP (1 mg/nostril) display impaired ability to recognize a juvenile intruder after a short period of time (30 min), spending as much time investigating the familiar juvenile rat during the second presentation as they did on the first encounter. This data corroborates early findings demonstrating that treatments that reduce the dopaminergic neurotransmission such as MPTP [107,125] and reserpine [121,122] inhibit short-term olfactory memory. Interestingly, the pre-treatment with caffeine $(10 \mathrm{mg} / \mathrm{kg} /$ day, i.p. $)$ during five consecutive days was able to prevent both the short-term social memory deficits and locomotor impairments observed at different periods after a single i.n. MPTP administration in rats (Fig. 5). Overall, from these limited results in this field, it appears that caffeine and selective adenosine $\mathrm{A}_{2 A}$ receptor antagonists might be particularly useful to restore impaired learning and memory processes in MPTP and reserpine-treated rodents.

Beyond the memory symptoms, approximately $90 \%$ of PD patients at early stage exhibit olfactory dysfunction unrelated to the use of anti-PD medications (e.g., L-DOPA, dopamine agonists, anticholinergic compounds) [102]. Although no consistent evidence for the direct involvement of adenosine receptors in the olfactory deficits observed in PD has to date been documented, some indirect evidence allows one to speculate about the potential of caffeine and selective adenosine $\mathrm{A}_{2 A}$ receptor antagonists to interfere with olfactory functions. Kaelin-Lang and colleagues [126] demonstrated an high expression of adenosine $\mathrm{A}_{2 A}$ receptors in the granular cells of the accessory olfactory bulb of rodents. However, the functional importance of these receptors is still unknown. In addition, Hadfield [127] has demonstrated that caffeine, through the blockade of adenosine receptors, modulates the release of different neurotransmitters in the olfactory bulb of rodents, including dopamine, which plays a critical role in olfactory processing [128,129]. Furthermore, Prediger et al. [114] demonstrated that the acute administration of caffeine (10 and $30 \mathrm{mg} / \mathrm{kg}$, i.p.) or the selective adenosine $\mathrm{A}_{2 A}$ receptor antagonist ZM241385 (0.5 and $1.0 \mathrm{mg} / \mathrm{kg}$, i.p.), but not the selective $\mathrm{A}_{1}$ receptor antagonist DPCPX, improved the olfactory discrimination deficits in 12 month-old rats. Thus, this study provides the first evidence indicating that adenosine $\mathrm{A}_{2 A}$ receptors play a critical role in the facilitatory effect of caffeine on olfactory discrimination in middle aged rats. Additional research is needed to clarify the mechanism underlying the blockade of adenosine $\mathrm{A}_{2 A}$ receptors by caffeine which enhances the olfactory function in rodents. 
A

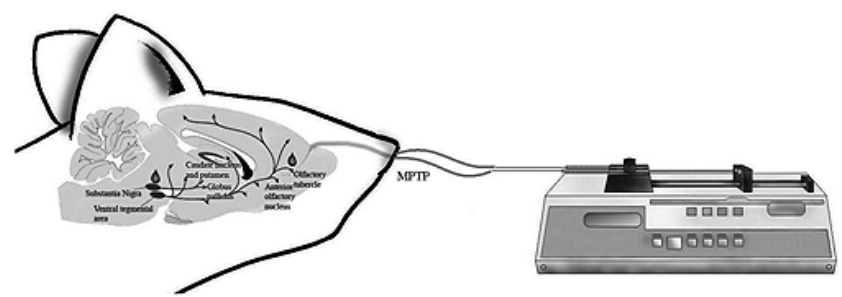

C

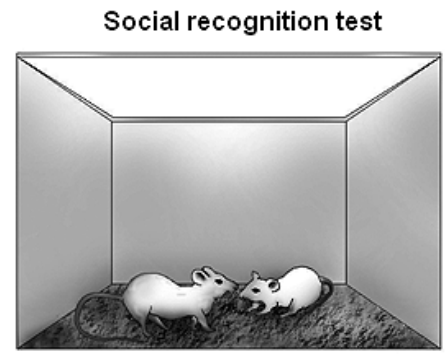

E

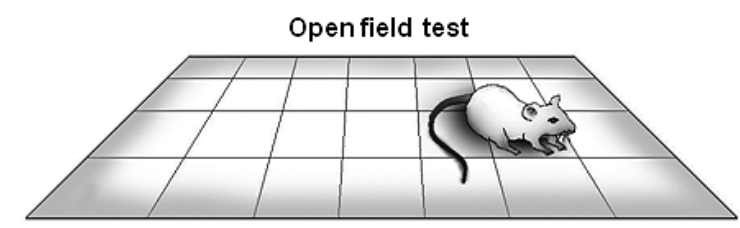

B

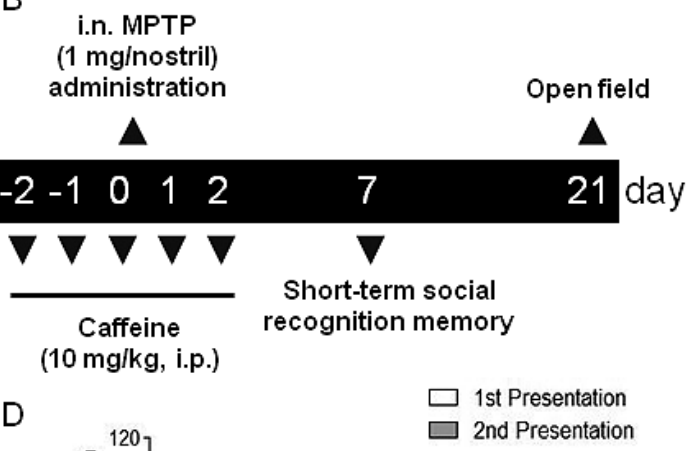

$\mathrm{F}$

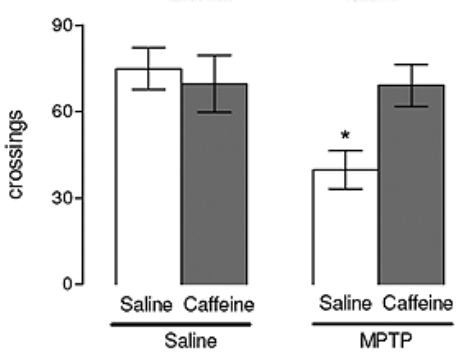

Fig. 5. (A) Schematic procedures of the intranasal (i.n.) administration of MPTP (1 mg/nostril) in rats [105,106]. (B) Time course of cognitive and motor behavioral tests evaluated in the intranasal MPTP rat model of Parkinson's disease. Pre-treatment with caffeine (10 mg/kg/day, i.p.) during 5 consecutive days prevented the (D) cognitive (social memory test) and (F) motor (open field test) impairments induced by i.n. MPTP administration in rats. $* \mathrm{P}<0.05$ comparing saline and caffeine-treated groups.

Depressive disorders commonly occur in PD patients [101], affecting approximately $40 \%$ of patients at early stages of the disease [130]. Tadaiesky and coworkers [131] have demonstrated that that a partial striatal lesion with 6-OHDA induces depressivelike symptoms (e.g., anhedonia and behavioral despair) in rats. Cunha and colleagues [132] have recently reviewed the indirect evidence supporting a possible role of adenosine $\mathrm{A}_{2 A}$ receptors in psychiatric disorders. Thus, because $A_{2 A}$ receptor antagonists might have anti-depressant properties [133], it will be important to consider whether motor and subjective improvement reflects elevation of mood in PD patients.

Although research is at a very early stage, the findings reviewed above highlight the memory-, olfactoryand mood-enhancing properties of caffeine in rodents. Therefore, the performance of additional pre-clinical and clinical studies to verify the effects of caffeine and selective adenosine $\mathrm{A}_{2 A}$ receptor antagonists in the non-motor symptoms of PD appears to be a promising field.

\section{CONCLUSION}

The findings presented in this review strongly suggest caffeine and selective adenosine $\mathrm{A}_{2 A}$ receptor antagonists as non-dopaminergic candidates for symptomatic and potentially disease-modifying therapy in PD. Disease modification remains the most important goal in PD. Convergent epidemiological and preclinical data obtained in rodent models have suggested that caffeine may confer neuroprotection against the underlying dopaminergic neuron degeneration, and influence the onset and progression of PD. However, further studies are needed to demonstrate whether these 
neuroprotective effects are also extensive to non-human primate models of PD. Moreover, the exact molecular mechanisms by which the blockade of adenosine $\mathrm{A}_{2 A}$ receptors can protect dopaminergic neurons from degenerating remains to be elucidated. Indeed, the present data also suggest that caffeine, through the blockade of adenosine $\mathrm{A}_{2 A}$ receptors in striatopallidal neurons, can improve the motor deficits of PD and that $\mathrm{A}_{2 A}$ receptor antagonists such as istradefylline reduce OFF time and dyskinesia associated with standard 'dopamine replacement' treatments. Finally, recent experimental findings have indicated the potential of caffeine in the management of non-motor symptoms (e.g., olfactory, memory and psychiatric symptoms) of PD that do not improve with the current dopaminergic drugs. Altogether, the studies reviewed provide strong evidence that caffeine may represent a promising therapeutic tool in PD, thus being the first compound to restore both motor and non-motor early symptoms of $\mathrm{PD}$, together with a neuroprotective potential.

\section{ACKNOWLEDGMENTS}

The author gratefully acknowledges Dr. Marcelo M. S. Lima and the PhD students Aderbal S. Aguiar Jr. and Daniel Rial for their editorial assistance and professors Reinaldo N. Takahashi, Cláudio Da Cunha and Rodrigo A. Cunha for their expert comments. Some of the research reviewed in this article was supported by the Brazilian agencies Conselho Nacional de Desenvolvimento Científico e Tecnológico (CNPq), Coordenação de Aperfeiçoamento de Pessoal de Nível Superior (CAPES) and Fundação de Apoio à Pesquisa Científica e Tecnológica do Estado de Santa Catarina (FAPESC).

The author's disclosure is available online (http:// www.j-alz.com/disclosures/view.php?id=259).

\section{REFERENCES}

[1] Parkinson J (2002) An essay on the shaking palsy. 1817. J Neuropsychiatry Clin Neurosci 14, 223-236.

[2] Mayeux R (2003) Epidemiology of neurodegeneration. Annu Rev Neurosci 26, 81-104.

[3] Hirsch E, Graybiel AM, Agid YA (1988) Melanized dopamine neurons are differentially susceptible to degeneration in Parkinson's disease. Nature 334, 345-348.

[4] Allain H, Bentué-Ferrer D, Akwa Y (2008) Diseasemodifying drugs and Parkinson's disease. Prog Neurobiol 84, 25-39.
[5] Ahlskog JE, Muenter MD (2001) Frequency of levodoparelated dyskinesias and motor fluctuations as estimated from the cumulative literature. Mov Disord 16, 448-458.

[6] Braak H, Ghebremedhin E, Rub U, Bratzke H, Del Tredici K (2004) Stages in the development of Parkinson's diseaserelated pathology. Cell Tissue Res 318,121-134.

[7] Chaudhuri KR, Healy DG, Schapira AH; National Institute for Clinical Excellence (2006) Non-motor symptoms of Parkinson's disease: diagnosis and management. Lancet Neurol 5, 235-245.

[8] Ross GW, Abbott RD, Petrovitch H, Morens DM, Grandinetti A, Tung KH, Tanner CM, Masaki KH, Blanchette PL, Curb JD, Popper JS, White LR (2000) Association of coffee and caffeine intake with the risk of Parkinson disease. JAMA 283, 2674-2679.

[9] Ascherio A, Zhang SM, Hernan MA, Kawachi I, Colditz GA, Speizer FE, Willett WC (2001) Prospective study of caffeine consumption and risk of Parkinson's disease in men and women. Ann Neurol 50, 56-63.

[10] Saaksjarvi K, Knekt P, Rissanen H, Laaksonen MA, Reunanen A, Mannisto S (2008) Prospective study of coffee consumption and risk of Parkinson's disease. Eur J Clin Nutr 62 , 908-915.

[11] Ravina BM, Fagan SC, Hart RG, Hovinga CA, Murphy DD, Dawson TM, Marler JR (2003) Neuroprotective agents for clinical trials in Parkinson's disease: a systematic assessment. Neurology 60, 1234-1240.

[12] Ascherio A, Chen H, Schwarzschild MA, Zhang SM, Colditz GA, Speizer FE (2003) Caffeine, postmenopausal estrogen, and risk of Parkinson's disease. Neurology 60, 790-795.

[13] Xu K, Xu Y, Brown-Jermyn D, Chen JF, Ascherio A, Dluzen DE, Schwarzschild MA (2006) Estrogen prevents neuroprotection by caffeine in the mouse 1-methyl-4-phenyl-1,2,3,6tetrahydropyridine model of Parkinson's disease. J Neurosci 26, 535-541.

[14] Chen JF, Xu K, Petzer JP, Staal R, Xu YH, Beilstein M, Sonsalla PK, Castagnoli K, Castagnoli N Jr, Schwarzschild MA (2001) Neuroprotection by caffeine and A2A adenosine receptor inactivation in a model of Parkinson's disease. $J$ Neurosci 21, RC143.

[15] Kalda A, Yu L, Oztas E, Chen JF (2006) Novel neuroprotection by caffeine and adenosine A2A receptor antagonists in animal models of Parkinson's disease. J Neurol Sci 248, 9-15.

[16] Xu K, Xu YH, Chen JF, Schwarzschild MA (2002) Caffeine's neuroprotection against 1-methyl-4-phenyl-1,2,3,6tetrahydropyridine toxicity shows no tolerance to chronic caffeine administration in mice. Neurosci Lett 322, 13-16.

[17] Pierri M, Vaudano E, Sager T, Englund U (2005) KW-6002 protects from MPTP induced dopaminergic toxicity in the mouse. Neuropharmacology 48, 517-524.

[18] Ikeda K, Kurokawa M, Aoyama S, Kuwana Y (2002) Neuroprotection by adenosine A2A receptor blockade in experimental models of Parkinson's disease. J Neurochem 80, 262270.

[19] Cunha RA (2005) Neuroprotection by adenosine in the brain: From A1 receptor activation to A2A receptor blockade. Purinergic Signal 1, 111-134.

[20] Chen JF, Sonsalla PK, Pedata F, Melani A, Domenici MR, Popoli P, Geiger J, Lopes LV, de Mendonça A (2007) Adenosine A2A receptors and brain injury: broad spectrum of neuroprotection, multifaceted actions and "fine tuning" modulation. Prog Neurobiol 83, 310-331. 
[21] Pinna A, Corsi C, Carta AR, Valentini V, Pedata F, Morelli M (2002) Modification of adenosine extracellular levels and adenosine A2A receptor mRNA by dopamine denervation. Eur J Pharmacol 446, 75-82.

[22] Tomiyama M, Kimura T, Maeda T, Tanaka H, Kannari K, Baba M (2004) Upregulation of striatal adenosine A2A receptor mRNA in 6-hydroxydopamine-lesioned rats intermittently treated with L-DOPA. Synapse 52, 218-222.

[23] Rebola N, Rodrigues RJ, Lopes LV, Richardson PJ, Oliveira CR, Cunha RA (2005) Adenosine A1 and A2A receptors are co-expressed in pyramidal neurons and co-localized in glutamatergic nerve terminals of the rat hippocampus. Neuroscience 133, 79-83.

[24] Duarte JM, Oliveira CR, Ambrósio AF, Cunha RA (2006) Modification of adenosine A1 and A2A receptor density in the hippocampus of streptozotocin-induced diabetic rats. Neurochem Int 48, 144-150.

[25] Cunha GM, Canas PM, Oliveira CR, Cunha RA (2006) Increased density and synapto-protective effect of adenosine A2A receptors upon sub-chronic restraint stress. Neuroscience 141, 1775-1781.

[26] Jones PA, Smith RA, Stone TW (1998) Protection against kainate-induced excitotoxicity by adenosine A2A receptor agonists and antagonists. Neuroscience 85, 229-237.

[27] Behan WM, Stone TW (2002) Enhanced neuronal damage by co-administration of quinolinic acid and free radicals, and protection by adenosine A2A receptor antagonists. $\mathrm{Br} \mathrm{J}$ Pharmacol 135, 1435-1442.

[28] Popoli P, Pintor A, Domenici MR, Frank C, Tebano MT, Pezzola A, Scarchilli L, Quarta D, Reggio R, Malchiodi-Albedi F, Falchi M, Massotti M (2002) Blockade of striatal adenosine $\mathrm{A} 2 \mathrm{~A}$ receptor reduces, through a presynaptic mechanism, quinolinic acid-induced excitotoxicity: possible relevance to neuroprotective interventions in neurodegenerative diseases of the striatum. J Neurosci 22, 1967-1975.

[29] Gao Y, Phillis JW (1994) CGS 15943, an adenosine A2 receptor antagonist, reduces cerebral ischemic injury in the Mongolian gerbil. Life Sci 55, PL61-PL65.

[30] Phillis JW (1995) The effects of selective A1 and A2a adenosine receptor antagonists on cerebral ischemic injury in the gerbil. Brain Res 705, 79-84.

[31] Monopoli A, Lozza G, Forlani A, Mattavelli A, Ongini E (1998) Blockade of A2A adenosine receptors by SCH 58261 results in neuroprotective effects in cerebral ischaemia in rats. NeuroReport 9, 3955-3959.

[32] Chen JF, Huang Z, Ma J, Zhu J, Moratalla R, Standaert D, Moskowitz MA, Fink JS, Schwarzschild MA (1999) A2A adenosine receptor deficiency attenuates brain injury induced by transient focal ischemia in mice. J Neurosci 19, 91929200.

[33] Yu L, Huang Z, Mariani J, Wang Y, Moskowitz M, Chen JF (2004) Selective inactivation or reconstitution of adenosine $\mathrm{A} 2 \mathrm{~A}$ receptors in bone marrow cells reveals their significant contribution to the development of ischemic brain injury. Nat Med 10, 1081-1087.

[34] Fink JS, Kalda A, Ryu H, Stack EC, Schwarzschild MA, Chen JF, Ferrante RJ (2004) Genetic and pharmacological inactivation of the adenosine A2A receptor attenuates 3nitropropionic acid-induced striatal damage. J Neurochem 88, 538-544.

[35] Dall'Igna OP, Porciuncula LO, Souza DO, Cunha RA, Lara DR (2003) Neuroprotection by caffeine and adenosine A2A receptor blockade of beta-amyloid neurotoxicity. Br J Pharmacol 138, 1207-1209.
[36] Arendash GW, Schleif W, Rezai-Zadeh K, Jackson EK, Zacharia LC, Cracchiolo JR, Shippy D, Tan J (2006) Caffeine protects Alzheimer's mice against cognitive impairment and reduces brain beta-amyloid production. Neuroscience $\mathbf{1 4 2}$, 941-952.

[37] Arendash GW, Mori T, Cao C, Mamcarz M, Runfeldt M, Dickson A, Rezai-Zadeh K, Tan J, Citron BA, Lin X, Echeverria V, Potter H (2009) Caffeine reverses cognitive impairment and decreases brain amyloid-beta levels in aged Alzheimer's disease mice. J Alzheimers Dis 17, 661-680.

[38] Parsons CG, Danysz W, Quack G (1998) Glutamate in CNS disorders as a target for drug development: an update. Drug News Perspect 11, 523-569.

[39] Olney JW (1969) Brain lesions, obesity, and other disturbances in mice treated with monosodium glutamate. Science 164, 719-721.

[40] Bonfoco E, Krainc D, Ankarcrona M, Nicotera P, Lipton SA (1995) Apoptosis and necrosis: two distinct events induced, respectively, by mild and intense insults with N-methyl-Daspartate or nitric oxide/superoxide in cortical cell cultures. Proc Natl Acad Sci U S A 92, 7162-7166.

[41] Matute C, Domercq M, Sanchez-Gomez MV (2006) Glutamate-mediated glial injury: mechanisms and clinical importance. Glia 53, 212-224.

[42] Gołembiowska K, Konieczny J, Ossowska K, Wolfarth S (2002) The role of striatal metabotropic glutamate receptors in degeneration of dopamine neurons: review article. Amino Acids 23, 199-205.

[43] Marcoli M, Raiteri L, Bonfanti A, Monopoli A, Ongini E, Raiteri M, Maura G (2003) Sensitivity to selective adenosine A1 and A2A receptor antagonists of the release of glutamate induced by ischemia in rat cerebrocortical slices. Neuropharmacology 45, 201-210.

[44] O'Regan MH, Simpson RE, Perkins LM, Phillis JW (1992) The selective A2 adenosine receptor agonist CGS 21680 enhances excitatory transmitter amino acid release from the ischemic rat cerebral cortex. Neurosci Lett 138, 169-172.

[45] Melani A, Pantoni L, Bordoni F, Gianfriddo M, Bianchi L, Vannucchi MG, Bertorelli R, Monopoli A, Pedata F (2003) The selective A2A receptor antagonist SCH 58261 reduces striatal transmitter outflow, turning behavior and ischemic brain damage induced by permanent focal ischemia in the rat. Brain Res 959, 243-250.

[46] Pedata F, Corsi C, Melani A, Bordoni F, Latini S (2001) Adenosine extracellular brain concentrations and role of A2A receptors in ischemia. Ann NY Acad Sci 939, 74-84.

[47] Li XX, Nomura T, Aihara H, Nishizaki T (2001) Adenosine enhances glial glutamate efflux via A2a adenosine receptors. Life Sci 68, 1343-1350.

[48] Nishizaki T, Nagai K, Nomura T, Tada H, Kanno T, Tozaki H, Li XX, Kondoh T, Kodama N, Takahashi E, Sakai N, Tanaka K, Saito N (2002) A new neuromodulatory pathway with a glial contribution mediated via A2a adenosine receptors. Glia 39, 133-147.

[49] Lucin KM, Wyss-Coray T (2009) Immune activation in brain aging and neurodegeneration: too much or too little? Neuron 64, 110-122.

[50] Lawson LJ, Perry VH, Dri P, Gordon S (1990) Heterogeneity in the distribution and morphology of microglia in the normal adult mouse brain. Neuroscience 39, 151-170.

[51] Mayne M, Fotheringham J, Yan HJ, Power C, Del Bigio MR, Peeling J, Geiger JD (2001) Adenosine A2A receptor activation reduces proinflammatory events and decreases cell 
death following intracerebral hemorrhage. Ann Neurol 49, 727-735.

[52] Ohta A, Sitkovsky M (2001) Role of G-protein-coupled adenosine receptors in downregulation of inflammation and protection from tissue damage. Nature 414, 916-920.

[53] Sitkovsky MV (2003) Use of the A2A adenosine receptor as a physiological immunosuppressor and to engineer inflammation in vivo. Biochem Pharmacol 65, 493-501.

[54] Sitkovsky MV, Ohta A (2005) The 'danger' sensors that STOP the immune response: the A2 adenosine receptors? Trends Immunol 26, 299-304.

[55] Cunha RA, Chen JF, Sitkovsky M (2007) Opposite modulation of peripheral inflammation and neuroinflammation: interaction between neurons and glia in aging and disease. In Interaction Between Neurons and Glia in Aging and Disease. Malva JO, Rego AC, Cunha RA, Oliveira CR (eds). Springer, NY, pp. 53-79.

[56] Fiebich BL, Biber K, Lieb K, van Calker D, Berger M, Bauer J, Gebicke-Haerter PJ (1996) Cyclooxygenase-2 expression in rat microglia is induced by adenosine A2A receptors. Glia 18, 152-160.

[57] Brodie C, Blumberg PM, Jacobson KA (1998) Activation of the A2A adenosine receptor inhibits nitric oxide production in glial cells. FEBS Lett 429, 139-142.

[58] Yu L, Shen HY, Coelho JE, Araujo IM, Huang QY, Day YJ, Rebola N, Canas PM, Rapp EK, Ferrara J, Taylor D, Muller CE, Linden J, Cunha RA, Chen JF (2008) Adenosine A2A receptor antagonists exert motor and neuroprotective effects by distinct cellular mechanisms. Ann Neurol 63, 338-346.

[59] Obeso JA, Rodriguez-Oroz M, Marin C, Alonso F, Zamarbide I, Lanciego JL, Rodriguez-Diaz M (2004) The origin of motor fluctuations in Parkinson's disease: importance of dopaminergic innervation and basal ganglia circuits. Neurology 62, S17-30

[60] Morelli M, Di Paolo T, Wardas J, Calon F, Xiao D, Schwarzschild MA (2007) Role of adenosine A2A receptors in parkinsonian motor impairment and 1-DOPA-induced motor complications. Prog Neurobiol 83, 293-309.

[61] Schwarzschild MA, Agnati L, Fuxe K, Chen JF, Morelli M (2006) Targeting adenosine A2A receptors in Parkinson's disease. Trends Neurosci 29, 647-654.

[62] Shiozaki S, Ichikawa S, Nakamura J, Kitamura S, Yamada K, Kuwana Y (1999) Actions of adenosine A2A receptor antagonist KW-6002 on drug-induced catalepsy and hypokinesia caused by reserpine or MPTP. Psychopharmacology 147, 90-95.

[63] Hauber W, Neuscheler P, Nagel J, Muller CE (2001) Catalepsy induced by a blockade of dopamine D1 or D2 receptors was reversed by a concomitant blockade of adenosine A2A receptors in the caudate-putamen of rats. Eur J Neurosci 14, 1287-1293.

[64] Fuxe K, Ungerstedt U (1974) Action of caffeine and theophyllamine on supersensitive dopamine receptors: considerable enhancement of receptor response to treatment with DOPA and dopamine receptor agonists. Med Biol 52, 48-54.

[65] Herrera-Marschitz M, Casas M, Ungerstedt U (1988) Caffeine produces contralateral rotation in rats with unilateral dopamine denervation: comparisons with apomorphineinduced responses. Psychopharmacology 94, 38-45.

[66] Fenu S, Morelli M (1998) Motor stimulant effects of caffeine in 6-hydroxydopamine-lesioned rats are dependent on previous stimulation of dopamine receptors: a different role of D1 and D2 receptors. Eur J Neurosci 10, 1878-1884.
[67] Casas M, Prat G, Robledo P, Barbanoj M, Kulisevsky J, Jané F (1999) Repeated co-administration of caffeine and bromocriptine prevents tolerance to the effects of caffeine in the turning behavior animal model. Eur Neuropsychopharmacol 9, 515-521.

[68] Fenu S, Pinna A, Ongini E, Morelli M (1997) Adenosine A2A receptor antagonism potentiates L-DOPA-induced turning behaviour and c-fos expression in 6- hydroxydopaminelesioned rats. Eur J Pharmacol 321,143-147.

[69] Koga K, Kurokawa M, Ochi M, Nakamura J, Kuwana Y (2000) Adenosine A(2A) receptor antagonists KF17837 and KW-6002 potentiate rotation induced by dopaminergic drugs in hemi-parkinsonian rats. Eur J Pharmacol 408, 249-255.

[70] Rose S, Ramsay Croft N, Jenner P (2007) The novel adenosine A2a antagonist ST1535 potentiates the effects of a threshold dose of 1-dopa in unilaterally 6-OHDA-lesioned rats. Brain Res 1133, 110-114.

[71] Jenner P (2003) A2A antagonists as novel non-dopaminergic therapy for motor dysfunction in PD. Neurology 61, S32-38.

[72] Lundblad M, Vaudano E, Cenci MA (2003) Cellular and behavioural effects of the adenosine A2a receptor antagonist KW-6002 in a rat model of 1-DOPA-induced dyskinesia. $J$ Neurochem 84, 1398-1410.

[73] Correa M, Wisniecki A, Betz A, Dobson DR, O'Neill MF, O'Neill MJ, Salamone JD (2004) The adenosine A2A antagonist KF17837 reverses the locomotor suppression and tremulous jaw movements induced by haloperidol in rats: possible relevance to parkinsonism. Behav Brain Res 148, 47-54.

[74] Wardas J, Konieczny J, Lorenc-Koci E (2001) SCH 58261, an A2A adenosine receptor antagonist, counteracts parkinsonian-like muscle rigidity in rats. Synapse 41, 160171.

[75] Kanda T, Jackson MJ, Smith LA, Pearce RK, Nakamura J, Kase H, Kase H, Kuwana Y, Jenner P (1998) Adenosine A2A antagonist: a novel antiparkinsonian agent that does not provoke dyskinesia in parkinsonian monkeys. Ann Neurol 43, 507-513.

[76] Grondin R, Bedard PJ, Hadj Tahar A, Gregoire L, Mori A, Kase H (1999) Antiparkinsonian effect of a new selective adenosine A2A receptor antagonist in MPTP-treated monkeys. Neurology 52, 1673-1677.

[77] Kanda T, Jackson MJ, Smith LA, Pearce RK, Nakamura J, Kase H, Kuwana Y, Jenner P (2000) Combined use of the adenosine A2A antagonist KW-6002 with 1-DOPA or with selective D1 or D2 dopamine agonists increases antiparkinsonian activity but not dyskinesia in MPTP-treated monkeys. Exp Neurol 162, 321-327.

[78] Bibbiani F, Oh JD, Petzer JP, Castagnoli N Jr, Chen JF, Schwarzschild MA, Chase TN (2003) A2A antagonist prevents dopamine agonist-induced motor complications in animal models of Parkinson's disease. Exp Neurol 184, 285-294.

[79] Bara-Jimenez W, Sherzai A, Dimitrova T, Favit A, Bibbiani F, Gillespie M, Morris MJ, Mouradian MM, Chase TN (2003) Adenosine A2A receptor antagonist treatment of Parkinson's disease. Neurology 61, 293-296.

[80] Hauser RA, Hubble JP, Truong DD (2003) Randomized trial of the adenosine A2A receptor antagonist istradefylline in advanced PD. Neurology 61, 297-303.

[81] Fernandez HH, Greeley DR, Zweig RM, Wojcieszek J, Mori A, Sussman NM; for the 6002-US-051 Study Group (2010) Istradefylline as monotherapy for Parkinson disease: Results of the 6002-US-051 trial. Parkinsonism Relat Disord 16, 1620 . 
[82] LeWitt PA, Guttman M, Tetrud JW, Tuite PJ, Mori A, Chaikin P, Sussman NM; 6002-US-005 Study Group (2008) Adenosine A2A receptor antagonist istradefylline (KW-6002) reduces "off" time in Parkinson's disease: a double-blind, randomized, multicenter clinical trial (6002-US-005). Ann Neurol 63, 295-302.

[83] Stacy M, Silver D, Mendis T, Sutton J, Mori A, Chaikin P, Sussman NM (2008) A 12-week, placebo-controlled study (6002-US-006) of istradefylline in Parkinson disease. Neurology 70, 2233-2240.

[84] Guttman M (2006) Efficacy of istradefylline in Parkinson's disease patients treated with levodopa with motor response complications: results of the KW-6002 US-018 study. Mov Disord 21, S585.

[85] Hauser RA, Shulman LM, Trugman JM, Roberts JW, Mori A, Ballerini R, Sussman NM; Istradefylline 6002-US-013 Study Group (2008) Study of istradefylline in patients with Parkinson's disease on levodopa with motor fluctuations. Mov Disord 23, 2177-2185.

[86] Graybiel AM, Aosaki T, Flaherty AW, Kimura M (1994) The basal ganglia and adaptive motor control. Science $\mathbf{2 6 5}$, 1826-1831.

[87] Ferré S, Fredholm BB, Morelli M, Popoli P, Fuxe K (1997) Adenosine-dopamine receptor-receptor interactions as an integrative mechanism in the basal ganglia. Trends Neurosci 20, $482-487$

[88] Surmeier DJ, Song WJ, Yan Z (1996) Coordinated expression of dopamine receptors in neostriatal medium spiny neurons. J Neurosci 16, 6579-6591.

[89] Ferré S, Karcz-Kubicha M, Hope BT, Popoli P, Burgueño J, Gutiérrez MA, Casadó V, Fuxe K, Goldberg SR, Lluis C, Franco R, Ciruela F (2002) Synergistic interaction between adenosine A2A and glutamate mGlu5 receptors: implications for striatal neuronal function. Proc Natl Acad Sci U S A 99, 11940-11945.

[90] Coccurello R, Breysse N, Amalric M (2004) Simultaneous blockade of adenosine A2A and metabotropic glutamate mGlu5 receptors increase their efficacy in reversing Parkinsonian deficits in rats. Neuropsychopharmacology 29, 14511461.

[91] Nishi A, Liu F, Matsuyama S, Hamada M, Higashi H, Nairn AC, Greengard P (2003) Metabotropic mGlu5 receptors regulate adenosine A2A receptor signaling. Proc Natl Acad Sci U S A 100, 1322-1327.

[92] Kachroo A, Orlando LR, Grandy DK, Chen JF, Young AB, Schwarzschild MA (2005) Interactions between metabotropic glutamate 5 and adenosine A2A receptors in normal and parkinsonian mice. J Neurosci 25, 10414-10419.

[93] Kurokawa M, Kirk IP, Kirkpatrick KA, Kase H, Richardson PJ (1994) Inhibition by KF17837 of adenosine A2A receptormediated modulation of striatal GABA and ACh release. $\mathrm{Br}$ J Pharmacol 113, 43-48.

[94] Dubois B, Pillon B (1997) Cognitive deficits in Parkinson's disease. J Neurol 244, 2-8.

[95] Bosboom JL, Stoffers D, Wolters ECh (2004) Cognitive dysfunction and dementia in Parkinson's disease. J Neural Transm 111, 1303-1315.

[96] Stebbins GT, Gabrieli JDE, Masciari F, Monti L, Goetz CG (1999) Delayed recognition memory in Parkinson's disease: a role for working memory? Neuropsychologia 37, 503-510.

[97] Lewis SJG, Dove A, Robbins TW, Barker RA, Owen AM (2003) Cognitive impairments in early Parkinson's disease are accompanied by reductions in activity in frontostriatal neural circuitry. J Neurosci 23, 6351-6356
[98] Bondi MW, Kaszniak AW (1991) Implicit and explicit memory in Alzheimer's disease and Parkinson's disease. J Clin Exp Neuropsychol 13, 339-358.

[99] Dujardin K, Laurent B (2003) Dysfunction of the human memory systems: role of the dopaminergic transmission. Curr Opin Neurol 16, S11-S16.

[100] Zgaljardic DJ, Foldi NS, Borod JC (2004) Cognitive and behavioral dysfunction in Parkinson's disease: neurochemical and clinicopathological contributions. J Neural Transm 111, 1287-1301.

[101] Schrag A (2004) Psychiatric aspects of Parkinson's disease: an update. J Neurol 251, 795-804.

[102] Doty RL, Deems D, Stellar S (1988) Olfactory dysfunction in Parkinson's disease: a general deficit unrelated to neurologic signs, disease state, or disease duration. Neurology 38, 12371244.

[103] Doty RL, Bromley SM, Stern MB (1995) Olfactory testing as an aid in the diagnosis of Parkinson's disease: development of optimal discrimination criteria. Neurodegeneration 4, 9397.

[104] Liberini P, Parola S, Spano PF, Antonini L (2000) Olfaction in Parkinson's disease: methods of assessment and clinical relevance. J Neurol 247, 88-96.

[105] Prediger RD, Batista LC, Medeiros R, Pandolfo P, Florio JC, Takahashi RN (2006) The risk is in the air: intranasal administration of MPTP to rats reproducing clinical features of Parkinson's disease. Exp Neurol 202, 391-403.

[106] Prediger RD, Rial D, Medeiros R, Figueiredo CP, Doty RL, Takahashi RN (2009) Risk is in the air: an intranasal MPTP (1-methyl-4-phenyl-1,2,3,6-tetrahydropyridine) rat model of Parkinson's disease. Ann N Y Acad Sci 1170, 629-636.

[107] Prediger RD, Aguiar AS Jr, Rojas-Mayorquin AE, Figueiredo CP, Matheus FC, Ginestet L, Chevarin C, Bel ED, Mongeau R, Hamon M, Lanfumey L, Raisman-Vozari $R$ (2010) Single intranasal administration of 1-methyl-4phenyl-1,2,3,6-tetrahydropyridine in c57Bl/6 mice models early preclinical phase of Parkinson's disease. Neurotox Res 17, 114-129.

[108] Da Cunha C, Gevaerd MS, Vital MA, Miyoshi E, Andreatini R, Silveira R, Takahashi RN, Canteras NS (2001) Memory disruption in rats with nigral lesions induced by MPTP: a model for early Parkinson's disease amnesia. Behav Brain Res 124, 9-18.

[109] Da Cunha C, Angellucci MEM, Canteras NS, Wonnacott S, Takahashi RN (2002) The lesion of the rat substantia nigra pars compacta dopamine neurons as a model for Parkinson's disease memory disabilities. Cell Mol Neurobiol 22, 227-237.

[110] Gevaerd MS, Miyoshi E, Silveira R, Canteras NS, Takahashi RN, Da Cunha C (2001) L-Dopa restores striatal dopamine level but fails to reverse MPTP-induced memory deficits in rats. Int J Neuropsychopharmacol 4, 361-370.

[111] Takahashi RN, Pamplona FA, Prediger RD (2008) Adenosine receptor antagonists for cognitive dysfunction: a review of animal studies. Front Biosci 13, 2614-2632.

[112] Kopf SR, Melani A, Pedata F, Pepeu G (1999) Adenosine and memory storage: effect of $\mathrm{A} 1$ and $\mathrm{A} 2$ receptor antagonists. Psychopharmacology 146, 214-219.

[113] Hauber W, Bareiss A (2001) Facilitative effects of an adenosine A1/A2 receptor blockade on spatial memory performance of rats: selective enhancement of reference memory retention during the light period. Behav Brain Res 118, 43-52.

[114] Prediger RD, Batista LC, Takahashi RN (2005) Caffeine reverses age-related deficits in olfactory discrimination and so- 
cial recognition memory in rats. Involvement of adenosine A1 and A2A receptors. Neurobiol Aging 26, 957-964.

[115] Prediger RD, Takahashi RN (2005) Modulation of short-term social memory in rats by adenosine $\mathrm{A} 1$ and $\mathrm{A} 2 \mathrm{~A}$ receptors. Neurosci Lett 376, 160-165.

[116] Dall'Igna OP, Fett P, Gomes MW, Souza DO, Cunha RA, Lara DR (2007) Caffeine and adenosine A2a receptor antagonists prevent beta-amyloid (25-35)-induced cognitive deficits in mice. Exp Neurol 203, 241-245.

[117] Gevaerd, MS, Takahashi RN, Silveira R, Da Cunha C (2001) Caffeine reverses the memory disruption induced by intranigral MPTP-injection in rats. Brain Res Bull 55, 101-106.

[118] Colpaert FC (1987) Pharmacological characteristics of tremor, rigidity and hypokinesia induced by reserpine in rat. Neuropharmacology 26, 1431-1440.

[119] Gerlach M, Riederer P (1996) Animal models of Parkinson's disease: an empirical comparison with the phenomenology of the disease in man. J Neural Transm 103, 987-1041.

[120] Alves CD, Andreatini R, da Cunha C, Tufik S, Vital MA (2000) Phosphatidylserine reverses reserpine-induced amnesia. Eur J Pharmacol 404, 161-167.

[121] Prediger RD, da Cunha C, Takahashi RN (2005) Antagonistic interaction between adenosine $\mathrm{A} 2 \mathrm{~A}$ and dopamine $\mathrm{D} 2$ receptors modulates the social recognition memory in reserpinetreated rats. Behav Pharmacol 16, 209-218.

[122] Aguiar AS Jr, Araújo AL, da-Cunha TR, Speck AE, Ignácio ZM, De-Mello N, Prediger RD (2009) Physical exercise improves motor and short-term social memory deficits in reserpinized rats. Brain Res Bull 79, 452-457.

[123] Doty RL (2008) The olfactory vector hypothesis of neurodegenerative disease: is it viable? Ann Neurol 63, 7-15.

[124] Franco J, Prediger RD, Pandolfo P, Takahashi RN, Farina M, Dafre AL (2007) Antioxidant responses and lipid per- oxidation following intranasal 1-methyl-4-phenyl-1,2,3,6tetrahydropyridine (MPTP) administration in rats: increased susceptibility of olfactory bulb. Life Sci 80, 1906-1914.

[125] Dluzen DE, Kreutzberg JD (1993) 1-Methyl-4-phenyl1,2,3,6-tetrahydropyridine (MPTP) disrupts social memory/recognition processes in the male mouse. Brain Res $\mathbf{6 0 9}$, 98-102.

[126] Kaelin-Lang A, Lauterburg T, Burgunder JM (1999) Expression of adenosine A2a receptor genes in the olfactory bulb and spinal cord of rat and mouse. Neurosci Lett 261, 189-191.

[127] Hadfield MG (1997) Caffeine and the olfactory bulb. Mol Neurobiol 15, 31-39.

[128] Doty RL, Risser JM (1989) Influence of the D2 dopamine receptor agonist quinpirole on the odor detection performance of rat before and after spiperone administration. Psychopharmacology 98, 310-315.

[129] Sallaz M, Jourdan F (1992) Apomorphine disrupts odourinduced patterns of glomerular activation in the olfactory bulb. Neuroreport 3, 833-836.

[130] Tolosa E, Compta Y, Gaig C (2007) The premotor phase of Parkinson's disease. Parkinsonism Relat Disord 13, S2-S7.

[131] Tadaiesky MT, Dombrowski PA, Figueiredo CP, CargninFerreira E, Da Cunha C, Takahashi RN (2008) Emotional, cognitive and neurochemical alterations in a premotor stage model of Parkinson's disease. Neuroscience 156, 830-840.

[132] Cunha RA, Ferré S, Vaugeois JM, Chen JF (2008) Potential therapeutic interest of adenosine A2A receptors in psychiatric disorders. Curr Pharm Des 14, 1512-1524.

[133] El Yacoubi M, Ledent C, Parmentier M, Bertorelli R, Ongini E, Costentin J, Vaugeois JM (2001) Adenosine A2A receptor antagonists are potential antidepressants: evidence based on pharmacology and A2A receptor knockout mice. $\mathrm{Br} J$ Pharmacol 134, 68-77. 